\title{
Burden, spectrum and outcomes of children with tuberculosis diagnosed at a district-level hospital in South Africa
}

\author{
K. du Preez, ${ }^{*}$ L. du Plessis, ${ }^{*}$ N. O’Connell, ${ }^{\dagger}$ A. C. Hesseling* \\ *Desmond Tutu TB Centre, Department of Paediatrics and Child Health, Faculty of Medicine and Health Sciences, \\ Stellenbosch University, Cape Town, 'Western Cape Province Department of Health, Khayelitsha District Hospital, \\ Cape Town, South Africa
}

SUM M ARY

SETTING: The Khayelitsha subdistrict has the highest burden of reported tuberculosis (TB) cases in Cape Town, Western Cape Province, South Africa.

OвJECTIVES: To characterise the TB burden, spectrum and treatment outcomes among children managed at a district-level hospital, the Khayelitsha District Hospital. DESIGN: Retrospective medical record review of all children (age $<13$ years) diagnosed with TB in January-July 2014. A lay health care worker completed daily surveillance and supported linkage to TB care. Symptoms and investigations at presentation, TB disease spectrum, referral pathways and outcomes were reported.

RESULTS: Most children were aged $\leqslant 2$ years (84/99, $85 \%), 18 / 96(19 \%)$ were infected with the human immunodeficiency virus, 31/91 (34\%) were malnourished and $80 / 99(81 \%)$ had pulmonary TB only. The majority of the children $(63 / 80,79 \%)$ presented with cough of acute onset ( $<2$ weeks). Only 5/36 (14\%) eligible child contacts had documentation of receiving isoniazid preventive therapy. Twelve $(13 \%)$ children had bacteriologically confirmed pulmonary TB. Overall, 93/ $97(96 \%)$ children successfully continued TB care after hospital discharge. Favourable TB treatment outcomes were recorded in only $77(78 \%)$ children.

CONCLUSIONS: Children with TB managed at this district-level hospital were young, and frequently had acute symptoms and substantial comorbidities. Missed opportunities for TB prevention were identified. Linkage to care support resulted in excellent continuation of TB care; however, treatment outcomes could be further improved.

KEY WORDS : diagnosis; HIV; pathways; presentation
THE 2016 WORLD HEALTH ORGANIZATION (WHO) global tuberculosis report indicated that South Africa remained one of the countries with the highest tuberculosis (TB) incidence in the world. ${ }^{1}$ In 2015 , children aged $<15$ years accounted for 29137 $(10 \%)$ cases of the overall national reported new and relapse TB case load $(n=287224)$ in South Africa. ${ }^{1}$

Children have a high risk of progressing to $\mathrm{TB}$ disease following infection with Mycobacterium tuberculosis and a high risk of developing severe forms of disease. ${ }^{2}$ In settings with a high burden of TB and human immunodeficiency virus (HIV), such as South Africa, paediatric TB contributes significantly to TB-related morbidity and mortality. ${ }^{3-5}$ HIVinfected children have higher rates of progression to TB disease and poorer TB treatment outcomes, even with the use of antiretroviral therapy. ${ }^{6,7}$

The paucibacillary nature of childhood TB disease

$\mathrm{KdP}$ and LdP contributed equally to the study and the article. in younger children and difficulties confirming diagnosis often result in children being managed on the basis of clinical symptoms and chest radiography (CXR) alone. This poses challenges, particularly in young children who may present with acute symptoms and atypical CXRs that may be difficult to interpret. ${ }^{8}$ In addition, respiratory specimen collection in young children is time-consuming and invasive. Children presenting at primary health care (PHC) facilities are therefore often referred for investigation and diagnosis at hospital level.

Data in the literature regarding the diagnosis, management and outcomes in paediatric $\mathrm{TB}$ are frequently from tertiary academic hospitals. ${ }^{9-13}$ Children managed at these centres are likely to have complicated or severe forms of disease, and possibly poor outcomes. The burden, spectrum and outcomes in children with TB managed at a district-level hospital might be very different, but these have not been well described in the literature. Insight into disease burden and spectrum managed at all levels of

Correspondence to: Karen du Preez, Desmond Tutu TB Centre, Department of Paediatrics and Child Health, Faculty of Medicine and Health Sciences, Stellenbosch University, Francie van Zijl Drive, Parow 7505, Cape Town, South Africa. email: karen_dupreez@sun.ac.za

Article submitted 22 December 2017. Final version accepted 6 April 2018. 
health care is important to ensure appropriate planning for resources at each level.

The objective of the present study was to characterise the burden and spectrum of disease, clinical presentation, diagnostic investigations and outcomes of children with TB diagnosed at a district-level hospital in a peri-urban, high TB-HIV burden setting in South Africa.

\section{SETTING}

In 2011, the estimated population of Khayelitsha was 391748 people; nearly one third were aged $<15$ years and $74 \%$ of households had a monthly income of $\leqslant 3200$ South African rand. ${ }^{14}$ The Khayelitsha health subdistrict contributed $3972(17 \%)$ to the total TB caseload (23 846) in the City of Cape Town during 2016; 2378 (59.9\%) were HIV-infected and 321 $(8 \%)$ were children aged $<15$ years (unpublished data, City Health, City of Cape Town). TB services are provided at nine PHC facilities in the subdistrict.

$\mathrm{KDH}$ has been providing primary and secondary level paediatric health care to children aged $<13$ years in the Khayelitsha subdistrict since February 2012. At the time of the present study, the $\mathrm{KDH}$ Paediatric Department consisted of one paediatrician (Department Head), a shared family physician and five medical officers. The department has 38 dedicated paediatric beds, a paediatric emergency centre, a 12-bed neonatal nursery and a 10-bed Kangaroo Mother Care unit. A paediatric out-patient clinic (POPD) operates 3 days per week. In 2014, KDH had 4290 paediatric admissions and 25607 POPD/emergency consultations. Children typically present to PHC facilities, and are referred to hospital for further investigations and management only if clinically indicated. Following a hospital diagnosis of TB, children are referred to their local PHC facility at discharge for treatment continuation. TB treatment outcome definitions are aligned with WHO recommendations, and outcomes are documented in the TB treatment registers.

The 2013 South African National TB Programme (SANTP) Childhood TB guidelines introduced a paediatric diagnostic algorithm based on one specimen sent for Xpert ${ }^{\circledR}$ MTB/RIF (Cepheid, Sunnyvale, CA, USA) testing in addition to smear and mycobacterial culture. ${ }^{15}$ In addition, HIV testing, the tuberculin skin test (TST), CXR and clinical examination remained part of the diagnostic algorithm. Until September 2014, Western Cape provincial guidelines restricted the use of Xpert to sputum, induced sputum and tracheal aspirates.

\section{METHODS}

During 2013-2014, as part of a childhood TB health systems strengthening study in Khayelitsha (Kid- care), a lay health care worker completed hospitalbased surveillance and linkage to care activities at $\mathrm{KDH}$. Daily surveillance was implemented in the paediatric wards, POPD and the Emergency Department to identify all children diagnosed with or treated for TB. Linkage to care activities included structured disease-specific education for parents/care givers, referral support for clinical personnel and telephone follow-up after hospital discharge.

All children (age $<13$ years) routinely diagnosed with TB at KDH from January to July 2014 were included. Data on demographics, clinical, diagnostic and referral pathways were collected through a retrospective review of medical records by a trained study nurse, and recorded on a standard case report form. Bacteriological records were accessed via the National Health Laboratory Services (NHLS) website. TB treatment outcome information was collated from hospital records, paper-based TB treatment registers at PHC facilities and provincial electronic TB registers (ETR.Net and EDRweb).

Malnutrition included any nutritional deficiencies (wasted, underweight, stunted, marasmus, kwashiorkor, malnutrition, severe acute malnutrition or moderate acute malnutrition) documented in clinical notes.

All data were dual captured into a central database using unique study identifiers, and were de-identified before analyses.

\section{Statistical analysis}

Statistical analysis was descriptive, and was performed using STATA v14 (StataCorp, College Station, TX, USA). Numbers and percentages are reported for categorical variables.

\section{Regulatory approvals}

The study protocol was approved by the Western Cape Department of Health, Cape Town, and the Human Research Ethics Committee, Stellenbosch University, Cape Town (N14/10/135).

\section{RESULTS}

The hospital-based clinical surveillance strategy identified 113 children with $\mathrm{TB}$ managed at $\mathrm{KDH}$ during the 7-month study period. Eleven children diagnosed outside the study period or admitted with an already established TB diagnosis were excluded. Of the remaining 102 children, 99 (97\%) hospital records were available for review.

Table 1 provides an overview of the clinical presentation and TB disease spectrum. Most children were aged $\leqslant 2$ years $(84,85 \%)$, and $69(67 \%)$ were male. Of the 88 children admitted, $70(81 \%)$ stayed in hospital for $\geqslant 3$ days. Cough $(80,81 \%)$ and failure to thrive/weight loss $(78,79 \%)$ were the most frequently reported symptoms. The majority of the 
Table 1 Demographics, clinical presentation and type of disease among children with TB diagnosed at a district-level hospital, Cape Town, South Africa $(n=99)$

\begin{tabular}{|c|c|}
\hline & $n(\%)^{*}$ \\
\hline $\begin{array}{l}\text { Age category, years } \\
<1 \\
1-2 \\
3-4 \\
\geqslant 5\end{array}$ & $\begin{array}{l}37(37) \\
47(48) \\
9(9) \\
6(6)\end{array}$ \\
\hline $\begin{array}{l}\text { Male sex } \\
\text { Admitted to hospital as in-patient }{ }^{\dagger}\end{array}$ & $\begin{array}{l}69 / 98(67) \\
88(89)\end{array}$ \\
\hline $\begin{array}{l}\text { Duration of hospitalisation, days } \\
<3 \\
3-6 \\
7-13 \\
>14 \\
\text { More than } 5\end{array}$ & $\begin{array}{c}16 / 86(18) \\
46 / 86(54) \\
16 / 86(19) \\
8 / 86(9) \\
5 / 99\end{array}$ \\
\hline $\begin{array}{l}\text { Symptoms and signs suggestive of TB recorded } \\
\text { Cough, weeks } \\
\geqslant 2 \\
<2 \\
\text { Failure to thrive or weight loss } \\
\text { Failure to thrive with/without weight loss } \\
\text { Only weight loss } \\
\text { Fever, weeks } \\
\geqslant 2 \\
<2\end{array}$ & $\begin{array}{c}80(81) \\
17 / 80(21) \\
63 / 80(79) \\
78(79) \\
70 / 78(90) \\
8 / 78(10) \\
62(62) \\
6 / 62(10) \\
56 / 62(90)\end{array}$ \\
\hline $\begin{array}{l}\text { History of TB contact } \\
\text { TB exposure history documented } \\
\text { Exposure to an infectious TB source case } \\
\text { documented } \\
\text { Documentation of IPT (in eligible children) }\end{array}$ & $\begin{array}{c}96(97) \\
38 / 96(40) \\
5 / 36(14)\end{array}$ \\
\hline $\begin{array}{l}\text { Nutritional status } \\
\text { Any form of malnutrition documented } \\
\text { Severe acute malnutrition }\end{array}$ & $\begin{array}{c}31 / 91(34) \\
8 / 91(9)\end{array}$ \\
\hline $\begin{array}{l}\text { Type of TB disease } \\
\text { PTB only } \\
\text { EPTB only } \\
\text { Both PTB and EPTB }\end{array}$ & $\begin{aligned} 79 & (80) \\
2 & (2) \\
18 & (18)\end{aligned}$ \\
\hline $\begin{array}{l}\text { Disseminated TB } \\
\text { TB meningitis } \\
\text { Miliary TB } \\
\text { Abdominal TB }\end{array}$ & $\begin{aligned} 18 & (18) \\
1 & (1) \\
2 & (1) \\
15 & (15)\end{aligned}$ \\
\hline
\end{tabular}

* The denominator is 99, except where otherwise indicated due to missing data.

+ $11(10 \%)$ children were seen and followed up at the KDH Paediatric OutPatient Department only. All 11 had full work-up, including bacteriologica testing.

${ }^{\ddagger}$ Of 38 children with a history of TB exposure, 36 (95\%) were aged $<5$ years or HIV-infected and therefore eligible for IPT according to the 2013 SANTP guidelines.

\$31/91 children were diagnosed with some form of nutritional deficiency during hospitalisation. We included all children clinically described by attending physicians as wasted, underweight, stunted, SAM, MAM, or diagnosed with marasmus, kwashiorkor or malnutrition.

${ }^{1}$ Children with abdominal TB mostly had uncomplicated abdominal lymph nodes (12/15) detected on ultrasound; splenic micro-abscesses were seen in $2 /$ 15 , and pericardial effusion on 1/15 ultrasounds.

$\mathrm{TB}=$ tuberculosis; IPT $=$ isoniazid preventive therapy; $\mathrm{PTB}=$ pulmonary $\mathrm{TB}$ $\mathrm{EPTB}=$ extra-pulmonary $\mathrm{TB} ; \mathrm{SAM}=$ severe acute malnutrition; $\mathrm{MAM}=$ moderate acute malnutrition; $\mathrm{KDH}=$ Khayelitsha District Hospital; SANTP South Africa National TB Programme; HIV = human immunodeficiency virus.

children with cough reported symptoms for $<2$ weeks (63/80, 79\%). Most children presenting with fever also reported acute onset of $<2$ weeks $(56 / 62,90 \%)$. History of TB exposure was documented in $96(97 \%)$ children; $58(60 \%)$ had no known TB exposure, and $38(40 \%)$ had household or other close contact TB exposure. Among children with reported TB exposure, $36 / 38$ were aged $<5$ years or were HIV-infected and therefore eligible for TB preventive therapy. However, only 5/36 (14\%) had documentation of receiving isoniazid preventive therapy (IPT) before hospital admission.

Malnutrition was documented in 31/91 (34\%) children, $8(9 \%)$ with severe acute malnutrition. The spectrum of TB included $79(80 \%)$ children with only pulmonary TB (PTB), 2 (2\%) with only extrapulmonary TB (EPTB) and 18 (18\%) with both PTB and EPTB. Two children were diagnosed with miliary $\mathrm{TB}$ and one with $\mathrm{TB}$ meningitis.

Table 2 provides an overview of TB diagnostic investigations. HIV status was documented in 96 $(97 \%)$ children, of whom $18(19 \%)$ were HIVinfected. Of the $18 \mathrm{HIV}$-infected patients, $10(56 \%)$ were known to be infected before hospital admission (6 were on antiretrovirals at the time of hospital admission), and 7 (39\%) were newly diagnosed at the time of hospital presentation, including $5(71 \%)$ who were aged $\leqslant 18$ months.

Fifty-eight $(59 \%)$ children received a TST. Of 41 $(71 \%)$ children with a documented result, $20(49 \%)$ were TST-positive ( $\geqslant 5 \mathrm{~mm}$ in HIV-infected and $\geqslant 10$ $\mathrm{mm}$ in HIV-negative children). All children underwent CXR, with documented clinician reviews reported in $97 / 99$ (98\%). CXR was reported as 'suggestive of TB' in 95/97 (98\%) children. Of these, $78 / 95(82 \%)$ had 'typical CXR signs', defined in the SANTP guidelines as hilar nodes, expansile pneumonia, compression/collapse, pleural effusions, miliary TB, apical infiltrates or cavities. Hilar adenopathy was the most common finding on CXR $(61 / 78,78 \%)$. Respiratory specimens from 92 (93\%) children were sent for bacteriological investigation; most of the specimens $(n=84,91 \%)$ were gastric aspirates, 10 of which were collected successfully from out-patients in POPD. TB diagnosis was bacteriologically confirmed on respiratory specimens in $12(13 \%)$ children (Xpert-positive specimens, 2/10 [20\%]; MGIT [BD, Sparks, MD, USA] mycobacterial culture-positive specimens, 11/90 [12\%]).

Type of TB treatment, referral care pathways and treatment outcomes are given in Table 3. During initial presentation at hospital, $83(84 \%)$ children were started on anti-tuberculosis treatment. Of the 16 children followed up after the initial presentation without starting anti-tuberculosis treatment, 12 started treatment within 30 days and only $4(25 \%)$ had a $>30$-day delay in treatment initiation from initial presentation. Two of these children had positive mycobacterial cultures (culture took $>30$ days) and two did not improve clinically after oral antibiotics and follow-up. Most children (96, 97\%) were started on first-line drug regimens. The three children who started second-line multidrug-resistant TB (MDRTB) regimens either had bacteriologically confirmed resistance $(n=2)$ or reported MDR-TB exposure $(n=$ $1)$. 
Table 2 Diagnostic investigations completed for children diagnosed with TB at a district-level hospital, Cape Town, South Africa $(n=99)$

\begin{tabular}{|c|c|}
\hline & $n(\%)$ \\
\hline $\begin{array}{l}\text { HIV testing }(n=99) \\
\text { HIV status documented } \\
\text { HIV-negative } \\
\text { HIV-infected }\end{array}$ & $\begin{array}{r}96(97) \\
78 / 96(81) \\
18 / 96(19)\end{array}$ \\
\hline $\begin{array}{l}\text { Timing of HIV diagnosis in relation to hospital admission }(n=18) \\
\text { Known to be with HIV infection before hospital admission* } \\
\text { Diagnosed with HIV infection during hospital admission } \\
\text { Time of HIV diagnosis not documented }\end{array}$ & $\begin{array}{l}10 / 18(56) \\
7 / 18(39) \\
1 / 18(5)\end{array}$ \\
\hline $\begin{array}{l}\text { TST } \\
\text { Recorded that TST had been performed } \\
\text { Documentation of TST result } \\
\text { TST-positive }^{\S}\end{array}$ & $\begin{array}{r}58(59) \\
41 / 58(71) \\
20 / 41(49)\end{array}$ \\
\hline $\begin{array}{l}\text { CXR } \\
\text { Number of children recorded to have undergone CXR } \\
\text { CXR findings recorded by clinician } \\
\text { CXR reported as suggestive of TB } \\
\text { One or more typical CXR signs of TB reported according to SANTP guidelines"\# }\end{array}$ & $\begin{array}{r}99(100) \\
97 / 99(98) \\
95 / 97(98) \\
78 / 95(82)\end{array}$ \\
\hline $\begin{array}{l}\text { Bacteriological testing on respiratory samples } \\
\text { Children with results of respiratory bacteriological investigations at NHLS }\end{array}$ & $92(93)$ \\
\hline $\begin{array}{l}\text { Type of respiratory specimens sent for TB microbiological testing } \\
\text { First specimen gastric aspirate } \\
\text { First specimen sputum }\end{array}$ & $\begin{array}{l}84 / 92(91) \\
8 / 92(9)\end{array}$ \\
\hline $\begin{array}{l}\text { Number of respiratory specimens per child sent for TB investigations } \\
1 \\
2 \\
\geqslant 3\end{array}$ & $\begin{array}{l}16 / 92(16) \\
52 / 92(57) \\
24 / 92(25)\end{array}$ \\
\hline $\begin{array}{l}\text { Xpert }(n=92) \\
\text { Total number of patients who underwent Xpert } \\
\text { Positive Xpert } \\
\text { RIF resistance detected on Xpert result }\end{array}$ & $\begin{array}{r}10 / 92(11) \\
2 / 10(20) \\
1 / 10(10)\end{array}$ \\
\hline $\begin{array}{l}\text { Mycobacterial culture }\left(\mathrm{MGIT}^{\mathrm{TM}}\right)(n=92) \\
\text { Total number of patients who underwent culture } \\
\text { Positive } M \text {. tuberculosis culture } \\
\text { No susceptibility results available } \\
\text { Drug resistance identified on culture } \\
{ }^{\dagger \dagger}\end{array}$ & $\begin{array}{r}90(98) \\
11 / 90(12) \\
5 / 11(45) \\
1 / 11(9)\end{array}$ \\
\hline Total bacteriologically confirmed cases & 12/92 (13) \\
\hline
\end{tabular}

* 6/10 children known to be HIV-infected were on ART before hospital admission, 3 children not on ART were diagnosed within 1 month before admission.

${ }^{+}$Of the 7 diagnosed during admission, 5 were aged $\leqslant 18$ months.

${ }^{\ddagger}$ No information relating to HIV diagnosis documented in folder or available on NHLS.

$\S$ According to SANTP guidelines: HIV-negative $\geqslant 10 \mathrm{~mm}$; HIV-infected $\geqslant 5 \mathrm{~mm}$.

" CXR was reported as not being suggestive of TB $(n=2)$. Both children had extra-pulmonary TB only.

\# Typical CXR signs defined as hilar nodes (61/78, 78\%), expansile pneumonia (27/78, 35\%), pleural effusions (2/78, $3 \%)$, miliary TB $(2 / 78,3 \%)$, cavities (2/78, 3\%). Atypical CXR reported as suggestive of TB included lobar/paratracheal infiltrates or paratracheal nodes. CXR was only reported as suggestive of TB with no specific signs documented in 6 . $* *$ Culture-positive specimens were subject to drug susceptibility testing only if specifically requested by the clinician. ${ }^{+\dagger}$ Drug resistance pattern identified as isoniazid monoresistance.

TB = tuberculosis; HIV = human immunodeficiency virus; TST = tuberculin skin test; CXR = chest radiograph; SANTP = South Africa National TB Programme; NHLS = National Health Laboratory Service; RIF = rifampicin; MGIT ${ }^{\mathrm{TM}}=$ Mycobacteria Growth Indicator Tube; ART = antiretroviral treatment.

Most children 89 (90\%) were discharged to community PHC facilities for further treatment, and $79 / 89(89 \%)$ were scheduled for hospital follow-up at the POPD, although $63 / 89$ (80\%) had already been started on anti-tuberculosis treatment. Attendance of hospital follow-up visits was good $(67 / 79,85 \%)$. Of 10 children $(10 \%)$ referred for tertiary care, eight were referred back to $\mathrm{KDH}$ and eventually to a PHC facility for treatment completion. Of 97 children referred to PHC facilities, 93 (96\%) were successfully linked to community-based TB care following hospital diagnosis. Overall, 89/99 (90\%) were included in routine TB surveillance data (ETR.Net/EDRWeb).
Favourable TB treatment outcomes were recorded in $77(78 \%)$ children. Unfavourable outcomes included $11(11 \%)$ children lost to follow-up, $9(9 \%)$ not evaluated and $2(2 \%)$ transferred out.

\section{DISCUSSION}

Based on the data presented here, surveillance of paediatric TB at a district-level hospital provides important insights into the burden and spectrum of disease, including the basis for diagnosis in children managed for TB at this level of health care. The study identified a large burden of children diagnosed with 
Table 3 Type of anti-tuberculosis treatment, referral care pathways and TB treatment outcomes of children diagnosed with TB at a district-level hospital, Cape Town, South Africa ( $n=$ 99)

$n(\%)$

Type of anti-tuberculosis treatment initiated

Treated for drug-susceptible TB

Treated for drug-resistant TB*

Referral pathways at hospital discharge

Discharged to PHC facilities with a hospital POPD follow-up ${ }^{\dagger}$

Discharged to PHC facilities with no hospital follow-up

Referred to tertiary hospital $\left.\right|^{\ddagger}$

Continuity of TB care between hospital and PHC facilities TB care successfully linked with PHC facility following hospital discharge

TB treatment outcomes

Cured

Cureatment completed

Transferred out

LTFU?

$76(77)$

$2(2)$

$11(11)$

Not evaluated ${ }^{\#}$

$9(9)$

* Two cases were bacteriologically confirmed (1 culture-positive, isoniazid monoresistance; 1 Xpert-positive with rifampicin resistance); 1 treated due to history of exposure to MDR-TB.

${ }^{+}$Mainly for verification of culture results; $67 / 79$ (85\%) attended their scheduled follow-up.

${ }^{*}$ Characteristics of referred children were as follows: 3 HIV-infected (1 with disseminated MDR-TB, 1 with tuberculous meningitis and 1 with PTB) and 7 HIV-negative children ( 5 with PTB and 2 with disseminated TB). All these children had other comorbidities such as malnutrition and sepsis.

$\S$ Outcomes of $89 / 99(90 \%)$ of children were obtained from routine TB surveillance sources (ETR.Net and EDR.Web).

"Included 7 children with an LTFU outcome in ETR, and 4 children LTFU after hospital discharge before accessing care at the PHC clinic.

\# Included children with no documented outcomes, as well as one child with an illegible outcome in the $\mathrm{PHC}$ register.

$\mathrm{TB}=$ tuberculosis; $\mathrm{PHC}=$ primary health care; $\mathrm{POPD}=$ Paediatric Out-patient Department; LTFU = lost to follow-up; MDR-TB = multidrug-resistant TB; HIV = human immunodeficiency virus; PTB = pulmonary TB.

TB at a district-level hospital in a high TB-HIV burden community, nearly 100 in a 7 -month period. Children were very young ( $85 \%$ were aged $<2$ years), and mostly presented with acute symptoms of short duration $(<2$ weeks). There was a high prevalence of HIV infection (19\%) and malnutrition (34\%), while significant missed opportunities for TB prevention were identified. Simple linkage to care activities successfully supported clinical continuity of TB care between district hospital and community-based health care services for nearly all children.

According to our study findings, children diagnosed with TB at this district hospital were thoroughly investigated for $\mathrm{TB}$, with almost all undergoing HIV testing, CXR and bacteriological investigations. The diagnostic process followed was appropriate based on national guidelines, with the exception of bacteriological testing. ${ }^{15}$ Provincial guidelines were only revised after the study at the end of 2014, allowing Xpert testing on gastric washings. Current guidelines recommend one Xpert test in addition to culture in all paediatric respiratory specimens. Although Xpert has lower sensitivity than culture to detect M. tuberculosis in children, it does allow for more rapid confirmation in acutely ill children. ${ }^{16,17}$ Most children in our study were investigated using culture, and given the lower sensitivity of Xpert we do not expect its roll-out to impact significantly on confirmation rates in this setting; it could, however, potentially reduce the time to diagnosis/confirmation.

Given the paucibacillary nature of paediatric TB, bacteriological confirmation of diagnosis in children treated for TB varies between $25 \%$ and $40 \% .{ }^{18-20}$ In our study, only $13 \%$ of children had a bacteriologically confirmed diagnosis, potentially indicating the lower proportion of children with complicated forms of intrathoracic (pulmonary) TB and disseminated TB. CXR was an important diagnostic tool for paediatric TB at this hospital. However, CXR interpretation, particularly in young children, can be challenging, even for experts. ${ }^{21-23}$ Taking into account the young age of children managed at this hospital, the associated comorbidities and the extremely high burden of $\mathrm{TB}$ in the surrounding community, one would expect a high index of suspicion for TB among clinicians. Some degree of overdiagnosis would therefore be expected and even acceptable, given the high risk of disease progression and severe forms of TB in young and HIV-infected children. ${ }^{2,6}$ Verification of diagnostic accuracy was beyond the scope of this study. Our results, however, highlight the urgent need for new, improved diagnostic tests that are child-friendly, more sensitive, specific and capable of informing real-time clinical management to reduce over- and underdiagnosis of $\mathrm{TB}$ in young children in high-burden settings.

TB care remains an important opportunity for HIV care in children. We observed that 7/18 (39\%) HIVinfected children were diagnosed with HIV after presenting to hospital with symptoms of TB (5 of them were aged $\leqslant 18$ months). This is of concern, as there has been a long-standing local Prevention of Mother-To-Child Transmission (PMTCT) programme, which reported only $2.6 \%$ vertical transmission in 2012-2013. ${ }^{24}$ A national review, however, has identified multiple losses in the implementation of the PMTCT service cascade in South Africa. ${ }^{25}$

We also identified missed opportunities for initiating TB preventive therapy in children with documented TB exposure, similar to findings from other studies in South Africa. ${ }^{26-28}$ As highlighted by a recent systematic review of child contact management in high-burden countries, high TB burden settings continue to face many challenges in the implementation of TB preventive therapy in child contacts. ${ }^{29}$ Strategies to support the implementation of preventive therapy should be prioritised to improve child contact management and prevention of $\mathrm{TB}$ in children. ${ }^{30}$

The majority of children diagnosed at this district hospital did not require further specialist/tertiary- 
level care, and were referred to community-based PHC facilities for further management and continuation of anti-tuberculosis treatment. However, the majority were admitted for $>3$ days, possibly reflecting the considerable severity of respiratory disease in this young cohort. Underpinned by the acute presentation of many children in our study, this highlights the need to better understand the role that TB plays in childhood pneumonia in high-burden settings. ${ }^{31}$ It also emphasises TB-related morbidity in young children and the need for adequate resource allocation at this level of health care.

Our results also showed successful follow-up in the majority of the children who were asked to attend out-patient hospital follow-up after discharge, mainly to facilitate verification of culture results. For patients for whom the decision to treat for TB had already been taken, follow-up could potentially have been more feasibly done at the PHC facilities. However, in those patients for whom the decision to treat was not yet established, hospital follow-up provided a valuable opportunity for a review of clinical and culture results.

Linkage to care activities resulted in $96 \%$ of children successfully continuing TB care after hospital discharge and $90 \%$ included in routine TB surveillance data (ETR.Net/EDRWeb). This is considerably higher than previously reported $(62 \%)$ by the large, tertiary-level hospital that serves $\mathrm{KDH}$; however, the tertiary-level hospital also caters to a larger catchment area. ${ }^{10}$ Favourable $\mathrm{TB}$ treatment outcomes were observed in nearly $80 \%$ of children. A study evaluating routine TB treatment register data in the City of Cape Town found a higher proportion of children $(85.9 \%)$ with favourable outcomes. ${ }^{32}$ The large proportion of children lost to follow-up during anti-tuberculosis treatment and with no evaluated outcome in our study is worrying. Interventions to strengthen treatment support and completeness of documentation could further improve outcomes.

This retrospective study had several limitations. Reliable surveillance data were only available for a fixed time period, resulting in a limited sample size. Data collection was limited to clinical documentation by routine health services staff. As an additional identification strategy, laboratory surveillance could have identified children missed by clinical hospital surveillance. However, as the paediatric department consists of a small team of clinicians, with one paediatric consultant conducting daily ward rounds and standardising care, we do not expect the lack of laboratory surveillance to substantially affect our results. Verification of diagnostic accuracy was beyond the scope of the study, but should be considered in future research. Despite these limitations, these routine data provide valuable insights into TB epidemiology in children at a district hospital, and give a more complete picture of the true burden of TB in South African children, complementary to data from PHC facilities and referral hospitals.

\section{CONCLUSIONS}

Investigation into the burden and spectrum of paediatric TB managed at all levels of health care services in high TB burden settings provides important information for hospital and public health managers. Our study provides a new perspective, characterising the epidemiology of paediatric TB at a district-level hospital. In our study, children with TB managed at a district-level hospital were very young, with substantial comorbidities. New diagnostic tools that can improve diagnostic accuracy in young children will greatly assist clinicians working in high-burden settings. Missed opportunities for TB prevention in child contacts were identified. Although most children successfully continued with TB care with simple linkage support activities, further research is needed to explore specific support interventions to improve TB treatment outcomes.

\section{Acknowledgements}

The authors thank the Harry Crossley Foundation, Cape Town, for supporting this study financially, the Paediatric Department at the Khayelitsha District Hospital, Cape Town, and D Bester and L Mafu from the Desmond Tutu TB Centre, Cape Town. KdP is supported by a South African Research Chairs Initiative grant to $\mathrm{ACH}$. The Kid-care project and linkage to care activities was funded by the University Research Co Grant Agreement (FY2013G87-4740) under the US Agency for International Development (674-C-00-09-00121-00; TB Programme in South Africa).

Conflicts of interest: none declared.

\section{References}

1 World Health Organization. Global tuberculosis report, 2016. WHO/HTM/TB/2016.13. Geneva, Switzerland: WHO, 2016.

2 Marais B J, Gie R P, Schaaf H S, et al. The natural history of childhood intra-thoracic tuberculosis: a critical review of literature from the pre-chemotherapy era. Int J Tuberc Lung Dis 2004; 8: 392-402.

3 Jenkins H E, Yuen C M, Rodriguez C A, et al. Mortality in children diagnosed with tuberculosis: a systematic review and meta-analysis. Lancet Infect Dis 2017; 17: 285-295.

4 Starke J R. Mortality in childhood tuberculosis: has there been progress? Lancet Infect Dis 2017; 17: 239-241.

5 Seddon J A, Shingadia D. Epidemiology and disease burden of tuberculosis in children: a global perspective. Infect Drug Resist 2014; 7: 153-165.

6 Hesseling A C, Cotton M F, Jennings T, et al. High incidence of tuberculosis among HIV-infected infants: evidence from a South African population-based study highlights the need for improved tuberculosis control strategies. Clin Infect Dis 2009; 48: 108-114.

7 Hesseling A C, Westra A E, Werschkull H, et al. Outcome of HIV infected children with culture confirmed tuberculosis. Arch Dis Child 2005; 90: 1171-1174.

8 Hesseling A C, Schaaf H S, Gie R P, Starke J R, Beyers N. A critical review of diagnostic approaches used in the diagnosis of childhood tuberculosis. Int J Tuberc Lung Dis 2002; 6: 10381045. 
9 Schaaf H S, Garcia-Prats A J, du Preez K, Rautenbach C, Hesseling A C. Surveillance provides insight into epidemiology and spectrum of culture-confirmed mycobacterial disease in children. Int J Tuberc Lung Dis 2016; 20: 1249-1256.

10 du Preez K, Schaaf H S, Dunbar R, et al. Incomplete registration and reporting of culture-confirmed childhood tuberculosis diagnosed in hospital. Public Health Action 2011; 1: 19-24.

11 Frigati L, Maskew M, Workman L, et al. Clinical predictors of culture-confirmed pulmonary tuberculosis in children in a high tuberculosis and HIV prevalence area. Pediatr Infect Dis J 2015; 34: e206-210.

12 Aketi L, Kashongwe Z, Kinsiona C, et al. Childhood tuberculosis in a sub-saharan tertiary facility: epidemiology and factors associated with treatment outcome. PLOS ONE 2016; 11: e0153914.

13 Tilahun G, Gebre-Selassie S. Treatment outcomes of childhood tuberculosis in Addis Ababa: a five-year retrospective analysis. BMC Public Health 2016; 16: 612.

14 Statistics South Africa. Provinicial profile: Western Cape. Census 2011.Pretoria: South Africa, SSA, 2014. http://www. statssa.gov.za/publications/Report-03-01-70/Report-03-01702011.pdf Accessed May 2018.

15 Department of Health, South Africa. Guidelines for the management of tuberculosis in children 2013. Pretoria, South Africa: DOH, 2013. www.health.gov.za/index.php/shortcodes/ 2015-03-29-10-42-47/2015-04-30-08-18-10/2015-04-30-0823-21 ?download=577: tb-in-children-guidelines Accessed May 2018.

16 Detjen A K, DiNardo A R, Leyden J, et al. Xpert MTB/RIF assay for the diagnosis of pulmonary tuberculosis in children: a systematic review and meta-analysis. Lancet Respir Med 2015; 3: 451-461.

17 Walters E, van der Zalm M M, Palmer M, et al. Xpert MTB/RIF on stool is useful for the rapid diagnosis of tuberculosis in young children with severe pulmonary disease. Pediatr Infect Dis J 2017; 36: 837-843.

18 Marais B J, Hesseling A C, Gie R P, Schaaf H S, Enarson D A, Beyers N. The bacteriologic yield in children with intrathoracic tuberculosis. Clin Infect Dis 2006; 42: e69-71.

19 Rachow A, Clowes P, Saathoff E, et al. Increased and expedited case detection by Xpert MTB/RIF assay in childhood tuberculosis: a prospective cohort study. Clin Infect Dis 2012; 54: 1388-1396.

20 Zar H J, Hanslo D, Apolles P, Swingler G, Hussey G. Induced sputum versus gastric lavage for microbiological confirmation of pulmonary tuberculosis in infants and young children: a prospective study. Lancet 2005; 365: 130-134.

21 Hatherill M, Hanslo M, Hawkridge T, et al. Structured approaches for the screening and diagnosis of childhood tuberculosis in a high prevalence region of South Africa. Bull World Health Organ 2010; 88: 312-320.

22 Kaguthi G, Nduba V, Nyokabi J, Onchiri F, Gie R, Borgdorff M. Chest radiographs for pediatric tb diagnosis: interrater agreement and utility. Interdiscip Perspect Infect Dis 2014; 2014: 291841.

23 Swingler G H, du Toit G, Andronikou S, van der Merwe L, Zar H J. Diagnostic accuracy of chest radiography in detecting mediastinal lymphadenopathy in suspected pulmonary tuberculosis. Arch Dis Child 2005; 90: 1153-1156.

24 Goga A, Jackson D, Singh M, Lombard C, for the SAPMTCTE study group. Early (4-8 weeks postpartum) population-level effectiveness of WHO PMTCT Option A, South Africa, 20122013. Pretoria, South Africa: South African Medical Research Council and National Department of Health of South Africa, 2015.

25 Woldesenbet S, Jackson D, Lombard C, et al. Missed opportunities along the prevention of mother-to-child transmission services cascade in South Africa: uptake, determinants, and attributable risk (the SAPMTCTE). PLOS ONE 2015; 10: e0132425.

26 Osman M, Hesseling A C, Beyers N, et al. Routine programmatic delivery of isoniazid preventive therapy to children in Cape Town, South Africa. Public Health Action 2013; 3: 199-203.

27 van Wyk S S, Reid A J, Mandalakas A M, et al. Operational challenges in managing isoniazid preventive therapy in child contacts: a high-burden setting perspective. BMC Public Health 2011; 11: 544.

28 Du Preez K, Hesseling A C, Mandalakas A M, Marais B J, Schaaf H S. Opportunities for chemoprophylaxis in children with culture-confirmed tuberculosis. Ann Trop Paediatr 2011; 31: 301-310.

29 Szkwarko D, Hirsch-Moverman Y, Du Plessis L, Du Preez K, Carr C, Mandalakas A M. Child contact management in high tuberculosis burden countries: a mixed-methods systematic review. PLOS ONE 2017; 12: e0182185.

30 Hill P C, Rutherford M E, Audas R, van Crevel R, Graham S M. Closing the policy-practice gap in the management of child contacts of tuberculosis cases in developing countries. PLOS MED 2011; 8: e1001105.

31 Oliwa J N, Karumbi J M, Marais B J, Madhi S A, Graham S M. Tuberculosis as a cause or comorbidity of childhood pneumonia in tuberculosis-endemic areas: a systematic review. Lancet Respir Med 2015; 3: 235-243.

32 Osman M, Lee K, Du Preez K, Dunbar R, Hesseling A C, Seddon J A. Excellent treatment outcomes in children treated for tuberculosis under routine operational conditions in Cape Town. Clin Infect Dis 2017; 65: 1444-1452. 
CONTEXTE : Le sousdistrict de Khayelitsha a le taux le plus élevé de cas de tuberculose (TB) rapportés au Cap, Province du Cap Ouest, Afrique du Sud.

O вJECTIF: Caractériser le poids, le spectre et l'évolution de la TB pédiatrique prise en charge dans l'hôpital de district de Khayelitsha.

SCHÉMAY : Revue rétrospective des dossiers médicaux de tous les enfants ( $<13$ ans) ayant eu un diagnostic de TB de janvier à juillet 2014. Un agent de santé de base a noté la surveillance quotidienne et la liaison au soutien des soins de TB. Les symptômes et investigations lors de la présentation, le spectre de la maladie TB, les parcours de référence et les résultats sont rapportés.

RÉSULTATS : La majorité des enfants (84/99; 85\%) avaient $\angle 2$ ans, 18/96 (19\%) étaient infectés par le virus de l'immunodéficience humaine, 31/91 (34\%) étaient malnutris et $80 / 99(81 \%)$ avaient seulement une TB pulmonaire. La majorité des enfants se sont présentés avec une toux de début brutal $(<2$ semaines) (63/80 ; $79 \%)$. Seulement $5 / 36(14 \%)$ enfants contacts éligibles avaient la preuve d'un traitement préventif par isoniazide. Douze $(\mathbf{1 3 \%})$ enfants avaient une TB pulmonaire bactériologiquement confirmée. Dans l'ensemble, 93/97 (96\%) enfants ont poursuivi avec succès le traitement de TB après la sortie de l'hôpital. Seulement 77 enfants $(78 \%)$ ont eu des résultats favorables du traitement de la TB.

CONCLUSION: Les enfants atteints de TB pris en charge dans cet hôpital de district ont été jeunes, ont fréquemment eu des symptômes aigus et des comorbidités importantes. Des opportunités manquées de prévention de la TB ont été identifiées. Le lien avec le soutien au traitement a abouti à une excellente continuité de la prise en charge de la TB, mais les résultats du traitement pourraient être améliorés.
MARCO DE REFERENCIA: El subdistrito de Khayelitsha notifica la más alta carga de morbilidad por tuberculosis (TB) en Ciudad del Cabo, en la Provincia Cabo Occidental de Suráfrica.

O BJETIVO: Describir la carga de morbilidad, los tipos de TB y los desenlaces terapéuticos en los casos de TB pediátrica tratados en el hospital distrital del distrito de Khayelitsha.

MÉ TO DO: Se llevó a cabo una revisión retrospectiva de las historias clínicas de todos los niños ( $<13$ años) con diagnóstico de TB tratados de enero a julio del 2014. Un trabajador de salud lego completaba la vigilancia diaria y reforzaba la vinculación al servicio de atención de la TB. Se describen los síntomas y las investigaciones iniciales, los tipos de enfermedad tuberculosa, los mecanismos de remisión y los desenlaces clínicos.

RESULTADOS: La mayoría de los niños (84/99; 85\%) tenía $\leqslant 2$ años de edad, 18/96 (19\%) sufrían infección por el virus de la inmunodeficiencia humana, 31/91 (34\%) presentaban malnutrición y 80/99 (81\%) presentaban TB de localización pulmonar exclusiva. La mayoría de los niños $(63 / 80 ; 79 \%)$ acudió con tos de presentación aguda ( $<2$ semanas). En solo cinco de los 36 contactos pediátricos $(14 \%)$ se pudo documentar que habían recibido tratamiento preventivo con isoniazida. En 12 niños $(13 \%)$ se obtuvo la confirmación bacteriológica del diagnóstico de TB pulmonar. En general, 93/97 niños (96\%) continuó de manera satisfactoria el tratamiento de la TB después del alta hospitalaria. Se registraron desenlaces favorables del tratamiento antituberculoso en solo 77 niños $(78 \%)$.

CONCLUSION: Los niños tratados por TB en este hospital distrital eran pequeños, con frecuencia presentaban síntomas agudos e importantes enfermedades concurrentes. Se reconocieron oportunidades desaprovechadas de prevenir la TB. La vinculación a los servicios de atención dio lugar a una excelente continuación del tratamiento de la TB, pero aún es posible mejorar los desenlaces terapéuticos. 